\title{
Out-of-hospital cardiac arrest: the prospect of E-CPR in the Maastricht region
}

\author{
A.S. Sharma · R.W.M. Pijls • P.W. Weerwind · T.S.R. Delnoij • W.C. de Jong • \\ A.P.M. Gorgels $\cdot$ J.G. Maessen
}

Published online: 4 January 2016

(C) The Author(s) 2016. This article is published with open access at Springerlink.com

\begin{abstract}
Aim The current outcome of out-of-hospital cardiac arrest (OHCA) patients in the Maastricht region was analysed with the prospect of implementing extracorporeal cardiopulmonary resuscitation (E-CPR).

Methods A retrospective analysis of adult patients who were resuscitated for OHCA during a 24-month period was performed.

Results 195 patients (age 66 [57-75] years, 82\% male) were resuscitated for OHCA by the emergency medical services and survived to admission at the emergency department. Survival to hospital discharge was $46.2 \%$. Notable differences between non-survivors and survivors were observed and included: age (70 [58-79] years) vs. (63 [55-72] years, $p=0.01$ ), chronic heart failure ( 18 vs. $7 \%, p=0.02$ ), shock-
\end{abstract}

A.S. Sharma and R.W.M. Pijls contributed equally to this work.

A.S. Sharma $(\bowtie) \cdot$ P.W. Weerwind · J.G. Maessen

Department of Cardiothoracic Surgery,

Maastricht University Medical Center,

P. Debyelaan 25,

6202 AZ Maastricht, The Netherlands

e-mail: ajay.sharma@maastrichtuniversity.nl

R.W.M. Pijls · T.S.R. Delnoij · A.P.M. Gorgels

Department of Cardiology,

Maastricht University Medical Centre,

Maastricht, The Netherlands

T.S.R. Delnoij

Departments of Cardiology and Intensive Care,

Maastricht University Medical Centre,

Maastricht, The Netherlands

W.C. de Jong

Department of Transplantation, Cardiovascular Research Institute

Maastricht, Maastricht University Medical Centre,

Maastricht, The Netherlands able rhythm (67 vs. $99 \%, p<0.01$ ), and return of spontaneous circulation (ROSC) at departure from the site of the arrest (46 vs. $99 \%, p<0.01$ ) and on arrival to the emergency department (43 vs. $98 \%, p<0.01$ ), respectively. Acute coronary syndrome was diagnosed in $32 \%$ of non-survivors vs. $59 \%$ among survivors, $p<0.01$. Therapeutic hypothermia was provided in non-survivors ( $20 \%)$ vs. survivors $(43 \%)$, $p<0.01$. Percutaneous coronary intervention (PCI) was performed in $14 \%$ of non-survivors while $52 \%$ of survivors received PCI $(p<0.01)$. No statistical significance was observed in terms of gender, witnessed arrest, bystander CPR, or automated external defibrillator deployed among the cohort. At hospital discharge, moderately severe neurological disability was present in six survivors.

Conclusion These observations are compatible with the notion that a shockable rhythm, ROSC, and post-arrest care improve survival outcome. Potentially, initiating E-CPR in the resuscitation phase in patients with a shockable rhythm and no ROSC might serve as a bridge to definite treatment and improve survival outcome.

Keywords Out-of-hospital cardiac arrest - Resuscitation · Shockable rhythm - Return of spontaneous circulation . Survivors $\cdot$ Extracorporeal cardiopulmonary resuscitation

\section{Introduction}

Out-of-hospital cardiac arrest (OHCA) in developed communities occurs more commonly and is a leading cause of death $[1,2]$. Recently, Chan et al. reported a survival rate of $8.6 \%$ in the United States [3]. In the Netherlands, reported survival rates are much higher, from $9 \%$ even up to $43 \%$ [4, 5]. Importantly, determinants that effectively favour better survival outcome include witnessed arrest, bystander car- 
diopulmonary resuscitation, shockable rhythm, use of automated electrical defibrillator, early return of spontaneous circulation (ROSC) and post-arrest care [2, 6-8]. Collectively, minimising time delays, resuscitation quality, intensive care, and treatment of the underlying cause of arrest increases survival outcome.

Alternatively, extracorporeal cardiopulmonary resuscitation (E-CPR) has been reported to improve survival outcome and organ recovery in refractory cardiac arrest [9-11]. Moreover, expansions in extracorporeal technology such as portable devices, circuitry and access to systemic circulation have led to further curiosity of its potential application [12]. E-CPR application is reported to increase the chances of successful defibrillation, preventing re-arrest due to postresuscitation myocardial dysfunction, thereby enabling subsequent interventions [11, 13]. Nevertheless, E-CPR requires minimalisation of time delay to establish qualitative invasive $\mathrm{CPR}$, and establish as a bridge to specific diagnostics and intervention.

Therefore, we aimed to analyse the current outcome of adult patients with OHCA following resuscitation in the Maastricht region with the prospects of implementing $\mathrm{E}-\mathrm{CPR}$ in the near future.

\section{Methods}

The observational study included adult OHCA patients who survived to emergency department admission at Maastricht University Medical Center, which lies in the southern part of the Dutch province of Limburg, between March 2012 and April 2014. The area is $203 \mathrm{~km}^{2}$ in size and has approximately 183,000 inhabitants (Statistics Netherlands 2013, www.cbs.nl). The Maastricht area is served by a university medical centre (Maastricht University Medical Center) and a network of emergency medical services (EMS). The local medical ethics review board approved the study with a waiver for obtaining the informed consent.

A call to the emergency number (112) alerts the regional EMS and other trained first responders including civilian SMS-alert responders and police personnel, equipped with an automatic external defibrillator (AED) in case of suspected OHCA. Two ambulances are dispatched, along with the first responder to perform basic life support. The EMS personnel provide standardised, mechanical CPR with an auto-pulse device (Zoll ${ }^{\circledR}$, Chelmsford, MA USA) and advanced life support.

\section{Data collection}

The data were collected by a researcher, who accessed the data collected and stored by the ambulance services, and by going through the electronic drive forms daily for resuscita- tions. The data gathered included Utstein-based recommendations on a form [14], while the ECG strips of the patients were attached to the drive forms of the patient. In case of AED use, the information on the AED application was retrieved from the AED (Corpuls ${ }^{3}$, GS Elektromed, Kaufering, Germany) and sent via an email to the researcher. When the SMS alert responder had provided basic life support, pertinent data were sent to the researcher, which were compiled and verified with the patient records. Pre-existing cardiac risk factors, cardiac comorbidities and past cardiac interventions were retrieved from the hospital records. Data on post-resuscitation management (diagnosis, therapeutic hypothermia or treatment such as percutaneous coronary interventions (PCI), coronary artery bypass graft, implantable cardioverter defibrillator (ICD) or pacemaker) were obtained from the hospital records. Survival was assessed at three time points, i.e. survival to emergency department, survival to hospital admission, and survival to hospital discharge.

\section{Definitions}

Arrests assumed to be of cardiac origin were included. Individuals with a do-not-resuscitate status, with signs of prolonged death and cardiac arrest of non-cardiac origin (for e.g. drowning, exsanguination), were excluded. The ECGs analysed by AED or taken by EMS paramedics were designated as the initial cardiac rhythm. The rhythms were classified as shockable (ventricular fibrillation, ventricular tachycardia), non-shockable (asystole, pulseless electrical activity) and non-threatening (sinus bradycardia, sinus tachycardia or sinus rhythm). ROSC was recorded at the time of departure from the site of the arrest and arrival at the emergency department. Neurological outcome to determine brain injury was scored by charting the modified Rankin Scale instead of the standard cerebral performance score to clearly distinguish mild to moderate neurological disability. The scoring was performed by assessing patient records at the time of discharge and at 1 month, 3 months, 6 months and 1 year follow-up. The modified Rankin Scale scores are allocated as: 0 -no symptoms, $1-$ no significant disability, 2-slight disability, 3-moderate disability, 4-moderately severe disability, 5—-severe disability, 6-dead [15].

\section{Statistical analysis}

Data were subjected to normality distribution, and accordingly continuous data are presented as medians [interquartile range] and/or means \pm standard deviation. Comparisons between two groups of continuous variables were performed using the Mann-Whitney $U$-test. Categorical variables were compared using Chi-square test with Fisher's exact test and expressed as percentages. Analyses were two-sided and dif- 
ferences with $p$-values $<0.05$ were considered statistically significant. The analyses were carried out using the Statistical Package for Social Sciences version 21.0 (IBM Corp., Armonk, NY, USA).

\section{Results}

Patients

A total number of 287 adult patients were identified with OHCA in the Maastricht region through the study period. After assessment of the records, 92 patients were excluded from the study (Fig. 1).

The study population included 195 patients, admitted to the emergency department with a cardiac cause of arrest. Patient demographics (Table 1) and pre-hospital resuscitation characteristics of OHCA are shown in Table 2. The patients were aged 66 [57-75] years and predominantly $(80 \%)$ male. The cardiac arrest event occurred at home (56\%) and was witnessed in $173(89 \%)$ patients. Subsequently 145 (74\%) patients received bystander CPR, EMS personnel initiated $\mathrm{CPR}$ in $26 \%$, and in $24 \%$ cases an

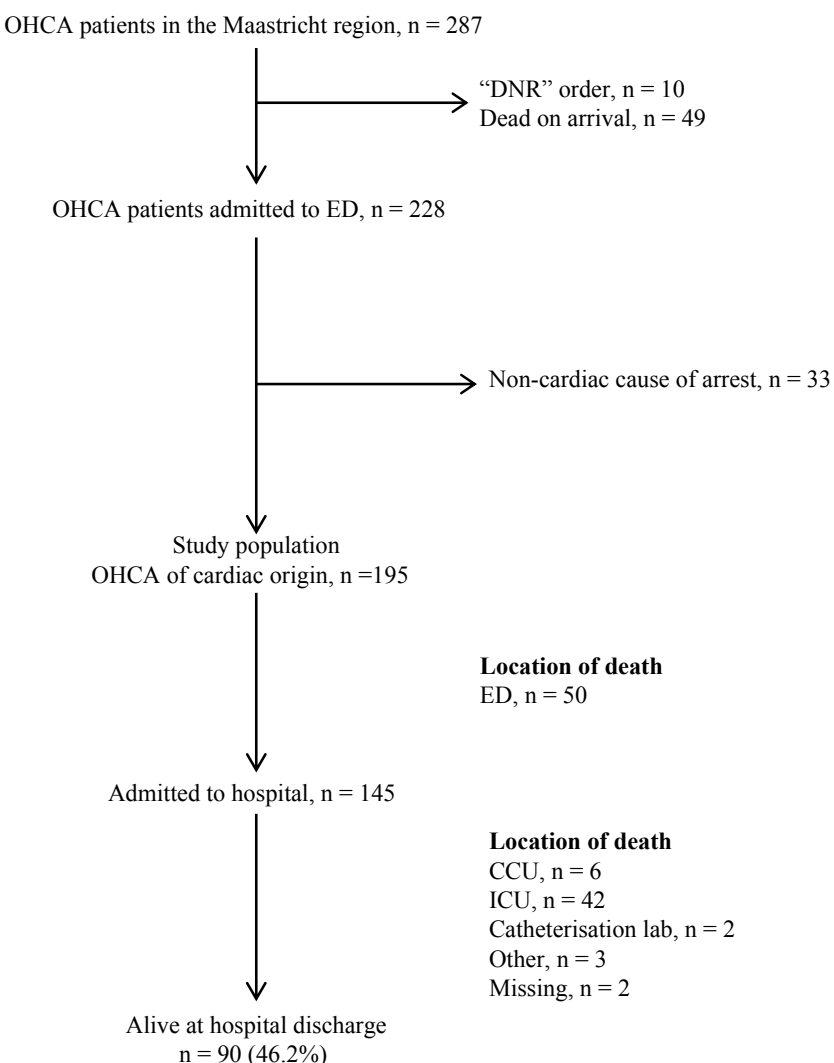

Fig. 1 Flow chart of patients with out-of-hospital cardiac arrest in Maastricht region (March 2012-April 2014). OHCA out-of-hospital cardiac arrest, $D N R$ do not resuscitate, $E D$ emergency department, $C C U$ coronary care unit, $I C U$ intensive care unit; other, ward
Table 1 Patient demographics of out-of-hospital cardiac arrest of cardiac origin who survived to emergency department admission

\begin{tabular}{|c|c|c|c|}
\hline & $\begin{array}{l}\text { Survivors } \\
n=90\end{array}$ & $\begin{array}{l}\text { Non-survivors } \\
n=105\end{array}$ & $p$-value ${ }^{a}$ \\
\hline Age (years) & & & 0.01 \\
\hline $\begin{array}{l}\text { Mean } \pm \text { standard } \\
\text { deviation }\end{array}$ & $63 \pm 12$ & $67 \pm 15$ & \\
\hline $\begin{array}{l}\text { Median [interquar- } \\
\text { tile range] }\end{array}$ & $63[55-72]$ & 70 [58-79] & \\
\hline Male gender, $n(\%)$ & $74(82)$ & $83(79)$ & 0.57 \\
\hline \multicolumn{4}{|l|}{$\begin{array}{l}\text { Cardiac risk factors, } \\
n(\%)\end{array}$} \\
\hline Diabetes & $12(14)$ & $22(22)$ & 0.11 \\
\hline Hypertension & $29(34)$ & $35(37)$ & 0.66 \\
\hline $\begin{array}{l}\text { Dyslipidaemia Previ- } \\
\text { ous cardiovascular } \\
\text { conditions, } n(\%)\end{array}$ & $14(17)$ & $18(19)$ & 0.64 \\
\hline $\begin{array}{l}\text { Cerebrovascular } \\
\text { accident }\end{array}$ & $4(5)$ & $6(6)$ & 0.67 \\
\hline Chronic heart failure & $6(7)$ & $18(18)$ & 0.02 \\
\hline $\begin{array}{l}\text { Myocardial } \\
\text { infarction }\end{array}$ & $22(25)$ & $33(32)$ & 0.25 \\
\hline $\begin{array}{l}\text { Ventricular } \\
\text { fibrillation }\end{array}$ & $3(3)$ & $4(4)$ & 0.84 \\
\hline $\begin{array}{l}\text { Atrial fibrillation } \\
\text { Previous cardiac } \\
\text { interventions, } n(\%)\end{array}$ & $7(8)$ & $17(17)$ & 0.07 \\
\hline PCI & $6(7)$ & $14(14)$ & 0.12 \\
\hline CABG & $8(9)$ & $8(8)$ & 0.78 \\
\hline Pacemaker & $2(2)$ & $0(0)$ & 0.13 \\
\hline ICD & $1(1)$ & $8(8)$ & 0.03 \\
\hline
\end{tabular}

$P C I$ percutaneous coronary intervention, $C A B G$ coronary artery bypass grafting, $I C D$ implantable cardioverter defibrillator.

aFisher's exact or Chi-square test for categorical variables; MannWhitney $U$ test for continous variables.

AED was applied. Shockable rhythm was observed in 150 (77\%) patients. The EMS response time was 7 [5-9] min, the advanced cardiac life support was provided for 24 [1831 ] min, and at departure ROSC was achieved in $70 \%$ of the patients. Transport time to the emergency department was 12 [6-18] min and $61(58 \%)$ patients required continued resuscitation during transportation.

Pre-hospital characteristics of non-survivors in relation to survivors

Tables 1 and 2 show the characteristics of the survivors and the non-survivors admitted to the emergency department. The non-survivors were relatively older compared with the survivors (70 [58-79] years) vs. 63 [55-72] years, $p=0.01$ ), and chronic heart failure was present in $18 \mathrm{vs.} 7 \%(p=0.02)$, respectively. An initial shockable rhythm was recorded in 69 non-survivors $(67 \%)$ vs. 81 survivors $(90 \%), p<0.01$. Among the non-survivors $<50 \%$ achieved ROSC at departure from the site and on arrival to the emergency depart- 
Table 2 Pre-hospital resuscitation characteristics, aetiology and treatment of out-of-hospital cardiac arrest of cardiac origin who survived to emergency department admission

\begin{tabular}{|c|c|c|c|}
\hline & $\begin{array}{l}\text { Survivors } \\
n=90\end{array}$ & $\begin{array}{l}\text { Non-survivors } \\
n=105\end{array}$ & $p$-value ${ }^{\mathrm{a}}$ \\
\hline Location of arrest, $n(\%)$ & & & 0.79 \\
\hline Home & $52(59)$ & $60(57)$ & \\
\hline Public & $36(41)$ & $45(43)$ & \\
\hline Witnessed arrest, $n(\%)$ & $83(92)$ & $90(86)$ & 0.15 \\
\hline Bystander CPR, $n(\%)$ & $68(76)$ & $77(73)$ & 0.72 \\
\hline AED deployed, $n(\%)$ & $22(24)$ & $24(23)$ & 0.80 \\
\hline Initial rhythm, $n(\%)$ & & & $<0.01$ \\
\hline Shockable & $81(90)$ & $69(67)$ & \\
\hline Non-shockable & $5(6)$ & $31(30)$ & \\
\hline Non-threatening ${ }^{\mathrm{b}}$ & $4(4)$ & $3(3)$ & \\
\hline $\begin{array}{l}\text { EMS arrival time since } \\
\text { call, min }\end{array}$ & & & 0.36 \\
\hline Mean \pm standard deviation & $7 \pm 6$ & $8 \pm 9$ & \\
\hline $\begin{array}{l}\text { Median [interquartile } \\
\text { range] }\end{array}$ & $6[5-9]$ & $6[4-9]$ & \\
\hline Defibrillation times, $n(\%)$ & & & $<0.01$ \\
\hline Mean \pm standard deviation & $1.8 \pm 2.0$ & $2.7 \pm 2.9$ & \\
\hline $\begin{array}{l}\text { Median [interquartile } \\
\text { range] }\end{array}$ & $1[0-3]$ & $2[0-4]$ & \\
\hline Auto-pulse, $n(\%)$ & $44(49)$ & $77(73)$ & $<0.01$ \\
\hline ROSC at departure, $n(\%)$ & $89(99)$ & $48(46)$ & $<0.01$ \\
\hline $\begin{array}{l}\text { Continued resuscitation, } \\
n(\%)\end{array}$ & $1(1)$ & $57(54)$ & \\
\hline $\begin{array}{l}\text { ACLS duration (min), } n \\
(\%)\end{array}$ & & & $<0.01$ \\
\hline Mean \pm standard deviation & $22 \pm 8$ & $23 \pm 11$ & \\
\hline $\begin{array}{l}\text { Median [interquartile } \\
\text { range] }\end{array}$ & 23 [18-27] & $24[16-31]$ & \\
\hline Intubation, $n(\%)$ & $44(49)$ & $81(77)$ & $<0.01$ \\
\hline \multicolumn{4}{|l|}{ Transport time, $\min$} \\
\hline Mean \pm standard deviation & $17 \pm 14$ & $16 \pm 14$ & 0.36 \\
\hline $\begin{array}{l}\text { Median [interquartile } \\
\text { range] }\end{array}$ & 15 [9-22] & 12 [7-19] & \\
\hline ROSC on arrival, $n(\%)$ & $88(98)$ & $45(43)$ & $<0.01$ \\
\hline $\begin{array}{l}\text { Continued resuscitation, } \\
n(\%)\end{array}$ & $2(2)$ & $59(56)$ & \\
\hline $\begin{array}{l}\text { Cardiac arrest aetiology, } \\
n(\%)\end{array}$ & & & $<0.01$ \\
\hline Acute coronary syndrome & $53(59)$ & $34(32)$ & \\
\hline $\begin{array}{l}\text { Chronic coronary artery } \\
\text { disease }\end{array}$ & $7(8)$ & $10(10)$ & \\
\hline Congestive heart failure & $4(4)$ & $12(11)$ & \\
\hline Conduction disorders & $16(18)$ & $8(8)$ & \\
\hline Structural disorders & $7(8)$ & $7(7)$ & \\
\hline Unknown & $3(3)$ & $34(32)$ & \\
\hline Therapeutic hypothermia & $39(43)$ & $21(20)$ & $<0.01$ \\
\hline \multicolumn{4}{|l|}{ Intervention ${ }^{\mathrm{c}}, n(\%)$} \\
\hline PCI & $47(52)$ & $15(14)$ & $<0.01$ \\
\hline CABG & $10(11)$ & $2(2)$ & $<0.01$ \\
\hline
\end{tabular}

Table 2 (continued)

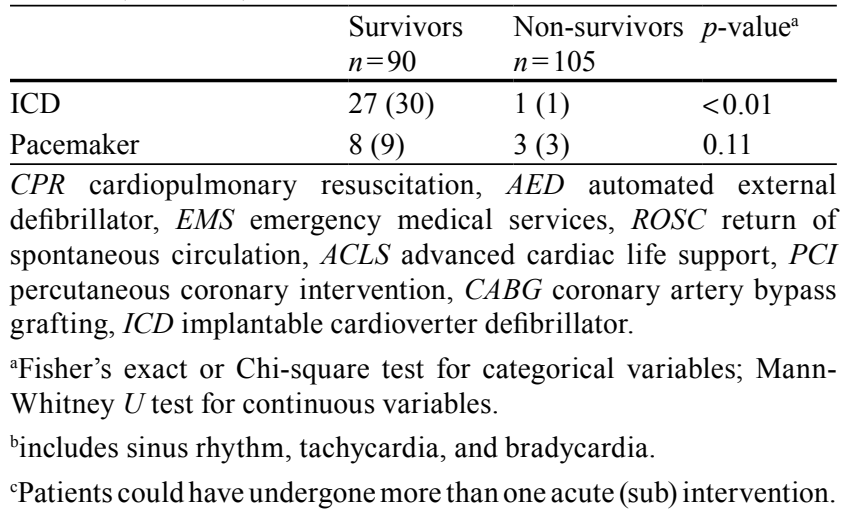

ment, while of the survivors nearly $100 \%$ achieved ROSC at departure and arrival, $p<0.01$, respectively. There was no statistical significance compared with survivors in terms of gender, witnessed arrest, bystander CPR, or use of AED.

\section{Diagnosis and treatment}

Following admission to the emergency department, 50 (26\%) patients died. Table 2 shows the cardiac aetiology and treatment of OHCA. In 87 (45\%) of the patients, cardiac arrest was precipitated by acute coronary syndrome, $60(31 \%)$ received therapeutic hypothermia and $62(32 \%)$ patients underwent a PCI. Among the non-survivors, 21 (20\%) received therapeutic hypothermia, ACS was diagnosed in $34(32 \%)$ and $15(14 \%)$ underwent PCI procedure.

\section{Survival and discharge destination}

Fifty-five patients died in hospital (Fig. 1) after an average stay of 8 days. Ninety (46.2\%) patients survived to hospital discharge after an average stay of 16 days following OHCA. After initial stabilisation and treatment, 17 patients were transferred to another hospital. Sixty-four (71\%) patients were discharged home and nine $(10 \%)$ to a nursing facility.

Neurological outcome and follow-up

Table 3 illustrates the neurological outcome of the survivors at the time of hospital discharge and follow-up at the end of 1 month, 6 months and 12 months following OHCA. The neurological outcome (assessed by the modified Rankin Scale) at hospital discharge was available for $61(68 \%)$ patients. Accordingly, $50 \%$ could carry out normal daily activities, while six $(10 \%)$ patients had moderately severe disability. 
Table 3 The modified Rankin Scale scores at hospital discharge and follow-up at 1,6 and 12 months

\begin{tabular}{lllll}
\hline $\begin{array}{l}\text { Modified } \\
\text { Rankin } \\
\text { Scale }\end{array}$ & $\begin{array}{l}\text { Discharge } \\
n=61\end{array}$ & $\begin{array}{l}1 \text { month } \\
n=43\end{array}$ & $\begin{array}{l}6 \text { months } \\
n=25\end{array}$ & $\begin{array}{l}12 \text { months } \\
n=18\end{array}$ \\
\hline 0 & $30(50 \%)$ & $27(63 \%)$ & $14(56 \%)$ & $10(56 \%)$ \\
1 & $13(21 \%)$ & $10(23 \%)$ & $7(28 \%)$ & $5(28 \%)$ \\
2 & $9(15 \%)$ & $4(10 \%)$ & $1(4 \%)$ & $1(6 \%)$ \\
3 & $3(5 \%)$ & $2(5 \%)$ & $3(12 \%)$ & $2(11 \%)$ \\
4 & $6(10 \%)$ & - & - & - \\
5 & - & - & - & -
\end{tabular}

Modified Rankin Scale: 0-no symptoms, 1-no significant disability, 2-slight disability, 3-moderate disability, 4moderately severe disability, 5-severe disability, 6-dead.

\section{Discussion}

In our out-of-hospital cardiac arrest observational study, covering the Maastricht region, more than $46 \%$ of the cardiac cohort admitted to the emergency department survived to hospital discharge. Evidently, shockable rhythm, ROSC on departure from site of arrest and arrival to the emergency department, shorter advanced cardiac life support duration, and post-arrest resuscitation care were the main findings for good survival outcome in the present study.

Recently, Boyce et al. reported a survival rate of $43 \%$ in patients admitted to hospital due to cardiac and noncardiac causes in the Leiden region [4]. In an earlier study reported from the Amsterdam region, survival rate to hospital discharge was 9\% [5].The varying survival outcome has been ascribed to regional variations following resuscitation efforts for OHCA and study design $[1,7,8]$. These described variations include but are not limited to population demographics, culture, competing illness, but also post-arrest care [16]. Despite all these regional variations, a trend towards a better outcome reflects improvements in the 'chain of survival' [6], as compared with the approximate $6 \%$ reported from an earlier study in the $1990 \mathrm{~s}$, from the Maastricht region [17]. In nearly $75 \%$ of the non-EMS witnessed cardiac arrests in the present study, a bystander provided basic CPR. It is known that bystander CPR maintains a state of shockable rhythm, which could double the chances of survival [5]. This finding is high compared to other Utstein reports [4-6], which is probably due to public awareness and alert systems in the region. Hence, early CPR determines the subsequent course of events. A state of shockable rhythm predicts better survival chances [18]. We observed a shockable rhythm to be most evident among the survivors $(90 \%)$. It is likely that an increased number of bystander CPRs in the acute phase of a cardiac event maintained a shockable rhythm. Furthermore, a correlation between shockable rhythm and ROSC has been described by Sasson and colleagues [2]. They reported that with a shockable initial rhythm, ROSC was achieved in $50 \%$ of
OHCA. In the ARREST study, Waalewijn et al. observed that $43 \%$ of patients with a shockable rhythm achieved ROSC, while $13 \%$ of patients with a non-shockable rhythm attained ROSC [5]. Therefore, the presence of a shockable rhythm might influence the duration of resuscitation and even the subsequent course of clinical management.

Recently, structured post-arrest care and its effect on the OHCA outcomes has been gathering attention, including the provision of therapeutic hypothermia, early cardiac intervention and neurological prognostication $[1,3,18]$. In our study $43 \%$ of survivors were cooled down with therapeutic hypothermia comparable with $47 \%$ of the survivors in the study by Boyce et al. [4]. Further, $43 \%$ of the patients admitted to hospital underwent an acute and/or sub-acute intervention. In the recent OHCA study from the Netherlands, $86 \%$ of patients admitted to the ICU or CCU underwent acute and/or sub-acute cardiac intervention [4]. The disparity might be due to the number of patients who died in our emergency department. A common understanding would be that patients with a reasonable chance to survive would receive further intervention. Potentially, early restoration of homeostasis with invasive CPR might serve as a bridge to definitive care in patient's refractory to continued resuscitation. Following recovery, at hospital discharge, 50\% of documented cases in the present study had a favourable neurological outcome. Bloom et al. reported a favourable outcome in about $20 \%$ of the ARREST study [18]. Plausibly, the presence of a shockable rhythm and early ROSC with consequent post-arrest care in eligible patients led to a better neurological outcome in our observational study.

One might wonder whether we could further optimise the chances of non-survivors towards better outcomes in the presented cohort. It is impossible to save every patient as some determinants remain unchanged, such as e.g. age and comorbidities. However, the modifiable determinant would be wider application of AED, thereby preventing a longer duration of no-flow (collapse to first defibrillation), which worsens the chances of survival by progressing into a non-shockable rhythm [8,9]. Alternatively, the presence of a non-shockable rhythm among non-survivors (30\%) might have been due to failure of ICD, battery discharge following defibrillation or the duration of resucitation [19, 20]. Since there has been limited resucitative and post-arrest care options for non-shockable rhythm [8], one can argue that implementation of E-CPR, restoring circulation and oxygenation, might prevent a state of non-shockable rhythm $[11,12]$. Therefore, it is tempting to speculate that a certain number of non-survivors in our cohort with survival determinants, such as witnessed arrest, received bystander CPR, or in shockable rhythm, would have likely benefited from invasive CPR in the event of unsustained ROSC, thereby, establishing a bridge to proven interventions. 
E-CPR is considered in cardiac arrest patients with a brief no-flow period when the condition leading to cardiac arrest is reversible or amenable to heart transplantation [10]. Additionally, E-CPR needs to be implemented in experienced centres, where the technique can be rapidly initiated [11, $12,21]$. In a prospective, observational study by Chen et al. survival outcome improved drastically in patients receiving E-CPR [11]. An up to $42 \%$ increase in survival rate was observed when E-CPR was implemented within 30 min of cardiac arrest. The implementation of E-CPR in a site like the emergency room would establish whole-body perfusion, providing a bridge to diagnosis and treatment, including controlled therapeutic hypothermia, cardiac intervention or heart transplant [11-13, 21, 22]. However, applying E-CPR may be futile in patients with previous cardiac comorbidities, i.e., chronic heart failure, structural heart disease or ICD failure. In the event of poor neurological prognosis, a decision for organ donation (based on advance directives and/or care provider's decision) could improve the quality of organ donors as a secondary outcome [22]. Therefore, assuming that refractory cardiac arrest may be caused by a treatable condition, engaging all temporising techniques to facilitate further diagnostics and therapy might be prospectively applied in a select patient population; this might potentially improve survival rate and organ recovery.

Limitations of our analysis include the lack of neurological scores for all survivors, this information was not available at the time of discharge and follow-up. These patients were transferred to other regional hospitals or lost to follow-up.

\section{Conclusion}

We reiterate that shockable rhythm, ROSC, and post-arrest care improves survival outcome. Potentially, initiating E-CPR in patients refractory to standard care on-scene or at the arrival to the emergency department might be a prospect for even better survival outcome.

Acknowledgments The authors acknowledge the expert assistance of $\mathrm{Mr}$ N. Otten from the ambulance central for South Limburg region for sharing their data.

\section{Funding None.}

Conflict of interests None declared.

Open Access This article is distributed under the terms of the Creative Commons Attribution License which permits any use, distribution, and reproduction in any medium, provided the original author(s) and the source are credited.

\section{References}

1. Proclemer A, Dobreanu D, Pison L, et al. Current practice in out-ofhospital cardiac arrest management. Europace. 2012;14:1195-8.

2. Sasson C, Rogers MA, Dahl J, et al. Predictors of survival from out-of-hospital cardiac arrest: a systematic review and meta-analysis. Cir Cardiovasc Qual Outcomes. 2010;3:63-81.

3. Chan PS, McNally B, Tang F, et al. Recent trends in survival from out-of-hospital cardiac arrest in the United States. Circulation. 2014;130:1876-82.

4. Boyce LW, Vliet Vlieland TP, Bosch J, et al. High survival rate of $43 \%$ in out-of-hospital cardiac arrest patients in an optimised chain of survival. Neth Heart J. 2015;23:20-5.

5. Waalewijn RA, de Vos R, Koster RW. Out-of-hospital cardiac arrests in Amsterdam and its surrounding areas: results from the Amsterdam resuscitation study (ARREST) in 'Utstein' style. Resuscitation. 1998;38:157-67.

6. Cummins RO, Ornato JP, Thies WH, et al. Improving survival from sudden cardiac arrest: the 'chain of survival' concept. Circulation. 1991;83:1832-47.

7. Zive D, Koprowicz K, Schmidt T, et al. Variation in out-of-hospital cardiac arrest resuscitation and transport practices in the Resuscitation Outcomes Consortium: ROC Epistry-Cardiac Arrest. Resuscitation. 2011;82:277-84.

8. Wang HE, Devlin SM, Sears GK, et al. Regional variations in early and late survival after out-of-hospital cardiac arrest. Resuscitation. 2012;83:1343-8.

9. Conseil français de réanimation cardiopulmonaire, Société française d'anesthésie et de réanimation, Société française de cardiologie, Société française de chirurgie thoracique et cardiovasculaire, Société française de médecine d'urgence, Société française de pédiatrie, Groupe francophone de réanimation et d'urgence pédiatriques, Société française de perfusion, Société de réanimation de langue française. Guidelines for indications for the use of extracorporeal life support in refractory cardiac arrest. French Ministry of Health. Ann Fr Anesth Reanim. 2009;28:182-90.

10. Cave DM, Gazmuri RJ, Otto CW, et al. Part 7: CPR techniques and devices: 2010 American Heart Association Guidelines for Cardiopulmonary Resuscitation and Emergency Cardiovascular Care. Circulation. 2010;122:720-8.

11. Chen YS, Lin JW, Yu HY, et al. Cardiopulmonary resuscitation with assisted extracorporeal life-support versus conventional cardiopulmonary resuscitation in adults with in-hospital cardiac arrest: an observational study and propensity analysis. Lancet. 2008;372:554-61.

12. Poppe M, Weiser C, Holzer M, et al. The incidence of 'load \& go' out-of-hospital cardiac arrest candidates for emergency department utilization of emergency extracorporeal life support: a one-year review. Resuscitation. 2015. doi:10.1016/j. resuscitation.2015.03.003.

13. Kagawa E, Dote K, Kato M, et al. Should we emergently revascularize occluded coronaries for cardiac arrest?: Rapid-response extracorporeal membrane oxygenation and intra-arrest percutaneous coronary intervention. Circulation. 2012;126:1605-13.

14. Jacobs I, Nadkarni V, Bahr J, et al. Cardiac arrest and cardiopulmonary resuscitation outcome reports: update and simplification of the Utstein templates for resuscitation registries. Resuscitation. 2004;63:233-49.

15. Rankin J. Cerebral vascular accidents in patients over the age of 60. II. Prognosis. Scott Med J. 1957;2:200-15.

16. Koster RW. Apples in Amsterdam and oranges in Leiden. Neth Heart J. 2015;23:18-9.

17. de Vreede-Swagemakers JJ, Gorgels AP, Dubois-Arbouw WI, et al. Out-of-hospital cardiac arrest in the 1990's: a population-based study in the Maastricht area on incidence, characteristics and survival. J Am Coll Cardiol. 1997;30:1500-5. 
18. Blom MT, Beesems SG, Homma PC, et al. Improved survival after out-of-hospital cardiac arrest and use of automated external defibrillators. Circulation. 2014;130:1868-75.

19. Reynolds JC, Frisch A, Rittenberger JC, et al. Duration of resuscitation efforts and functional outcome after out-of-hospital cardiac arrest: when should we change to novel therapies? Circulation. 2013;128:2488-94.

20. Frydland M, Kjaergaard J, Erlinge D, et al. Target temperature management of 33 degrees $\mathrm{C}$ and 36 degrees $\mathrm{C}$ in patients with out-of-hospital cardiac arrest with initial non-shockable rhythma TTM sub-study. Resuscitation. 2015;89:142-8.
21. Johnson NJ, Acker M, Hsu CH, et al. Extracorporeal life support as rescue strategy for out-of-hospital and emergency department cardiac arrest. Resuscitation. 2014;85:1527-32.

22. Fagnoul D, Taccone FS, Belhaj A, et al. Extracorporeal life support associated with hypothermia and normoxemia in refractory cardiac arrest. Resuscitation. 2013;84:1519-24. 